\title{
Comparision of Antibiotic Susceptility of Levofloxacin with Other Commonly Tested Antibiotics Against Salmonella Enterica Serovar (Typhi And Paratyphi A)
}

\author{
Chhetri $A,{ }^{1^{*}}$ Manandhar A, ${ }^{1}$ Shah $Y,{ }^{2}$ Simkhada $R C,{ }^{1}$ Paudyal $R,{ }^{1}$ Amatya $J,{ }^{1}$ Shrestha $J^{3}$ \\ ${ }^{1}$ Deparment of Microbiology, Kathmandu College of Science And Technology, Kalimati, Kathmandu, Nepal, \\ ${ }^{2}$ Everest International clinic and Research Center, Kalanki, Kathmandu, Nepal, \\ ${ }^{3}$ Department of Microbiology, Bir Hospital, Bhotahity, Kathmandu, Nepal
}

*Corresponding Author:

Mr. Arun Chhetri

Department of Microbiology

Kathmandu College of Science and Technology

Kalimati,Kathmandu, Nepal

Email: chhetriarun5@gmail.com

\section{Citation}

Chhetri A, Manandhar A, Shah Y, Simkhada RC, Paudyal $R$, Amatya J, Shrestha J. Comparision of Antibiotic Susceptility of Levofloxacin with Other Commonly Tested Antibiotics Against Salmonella Enterica Serovar (Typhi And Paratyphi A). Nepal Journal of Medical Sciences 2014;3(1):19-21.

\begin{abstract}
Background: Increasing antibiotic resistance of bacteria is a global problem. Fluoroquinolones are recommended as first line therapy for children and adults infected with Salmonella enterica serovar Typhi and Paratyphi A. The purpose of this study was to compare the antibiotic susceptibility pattern of different classes of antibiotics with levofloxacin from blood samples of suspected enteric fever patients visiting Bir hospital, Kathmandu.
\end{abstract}

Methods: Antibiotic susceptibility test was performed by Kirby-Bauer disc diffusion method as per Clinical Laboratory Standards Institute guideline.

Results: Among 50 isolates of Salmonella enterica, 39 (78\%) were $S$. Typhi and 11 (22\%) were S. Paratyphi A. All the isolates were tested against antibiotics, and all isolates were found sensitive to chloramphenicol and ceftriaxone whereas 3 isolates of $S$. Typhi were resistant to ciprofloxacin and 1 was resistant to levofloxacin. Fluoroquinolone resistant S. Paratyphi A was not observed. Among the 10 (20\%) multi drug resistant isolates, only 1 isolate was resistant to levofloxacin which was $S$. Typhi. Both $S$. Typhi (96.7\%) and S. Paratyphi A (89.4\%) were resistant to Nalidixic acid.

Conclusion: High level of nalidixic acid resistance and even some fluoroquinolone resistance showed that the treatment of the enteric fever cannot be relied on the fluoroquinolones.

Keywords: Levofloxacin; Nalidixic acid resistance; Salmonella enterica serovar (Typhi and Paratyphi A)

\section{Background:}

Increasing antibiotic resistance of bacteria is a global problem. The selection and administration of appropriate antibiotic against the bacterial disease is the most for the better patient management. It is better to perform the antibiotic susceptibility test for the screening of possible drug resistance and reduced susceptibility to certain antibiotics. ${ }^{1}$

Fluoroquinolones are recommended as first line therapy for children and adults infected with sensitive as well as multi drug resistant $\{(\mathrm{MDR})$ i.e. resistant to all three first 
line inexpensive antibiotics, chloramphenicol, amoxicillin and co-trimoxazole $\}$ S. Typhi and Paratyphi A. ${ }^{2}$ High level ciprofloxacin resistance has become common.

Levofloxacin has a broad spectrum of antimicrobial activity, and is effective against gram-positive and gram-negative bacteria. It may be a better choice than ciprofloxacin because of its excellent proven clinical efficacy and lower incidence of adverse gastrointestinal reactions in this kind of infection. ${ }^{3}$ Data regarding the efficacy of levofloxacin in the treatment of typhoid fever is at present not available. The purpose of this study was to perform antibiotic susceptibility test and compare the antibiotic susceptibility pattern of different classes of antibiotics with levofloxacin. In addition, the study also determined the levofloxacin susceptibility pattern of MDR isolates

\section{Methods:}

The study was carried out in Kathmandu Clinic during December 2010 to February 2011. Bacteria were isolated then identified by standard biochemical tests. Serotyping was performed by slide agglutination test using polyvalent and monovalent $\mathrm{O}$ and $\mathrm{H}$ antisera. S. Paratyphi A ( O2, H-a ), S. Paratyphi B ( 04, H-b ), S. Paratyphi C ( 06, H-C ) and S. Typhi ( O9, H-d ) ( Denka Seiken Co. Ltd. Tokyo, Japan ). 50 positive isolates of Salmonella enterica obtained from blood culture, confirmed by biochemical test along with slide agglutination were only included for the antibiotic susceptibility test. Antibiotic susceptibility test was performed by Kirby-Bauer disc diffusion method as per Clinical Laboratory Standards Institute guideline. Antibiotic discs tested were amoxicillin ( $10 \mathrm{mg}$ ), ceftriaxone ( 30mg ), chloramphenicol ( 30mg), ciprofloxacin ( $5 \mathrm{mg}$ ), cotrimoxazole ( $25 \mathrm{mg}$ ), levofloxacin ( $5 \mathrm{mg}$ ) and nalidixic acid ( 30mg ) (Hi Media Laboratory Ltd., Mumbai, India). The zone of inhibition was noted. Statistical analysis was performed using WIN PEPI Software ( version 7.9 ).

\section{Result:}

Out of 50 isolates of Salmonella enterica, 31 (62\%) were S. Typhi and 19 (38\%) were S. Paratyphi A. All the isolates were sensitive to chloramphenicol and ceftriaxone. NAR (94\%) was high and one isolate $(2 \%)$ was resistant to levofloxacin (Table 1).

Levofloxacin resistant S. Paratyphi A was not observed. Furthermore, antibiotic resistant and MDR S. Typhi $(\mathrm{n}=6)$ was higher than $S$. Paratyphi A (n=4) ( Table 2 ).

Ten $(20 \%)$ isolates were MDR of which, 9 MDR isolates were susceptible to levofloxacin whereas 1 was resistant.
The levofloxacin resistant isolate was MDR S. Typhi.

Table 1: Antibiotic susceptibility pattern of Salmonella enterica (Typhi and Paratyphi A)

\begin{tabular}{llcccc}
\hline \multirow{2}{*}{ S.n } & \multicolumn{1}{c}{ Antibiotic } & \multicolumn{2}{c}{ Resistant } & \multicolumn{2}{c}{ Sensitive } \\
& & No. & \% & No. & $\%$ \\
\hline 1 & Nalidixic acid (NA) & 47 & 94 & 3 & 6 \\
2 & Cotrimoxazole (COT) & 8 & 16 & 42 & 84 \\
3 & Ciprofloxacin (CIP) & 3 & 6 & 47 & 94 \\
4 & Chloramphenicol (C) & - & - & 50 & 100 \\
5 & Ceftriaxone (CTR) & - & - & 50 & 100 \\
6 & Amoxicillin (AMO) & 5 & 10 & 45 & 90 \\
7 & Levofloxacin (LE) & 1 & 2 & 49 & 98 \\
\hline
\end{tabular}

Table 2: Antibiotic susceptibility pattern of S. Paratyphi A vs. S. Typhi

\begin{tabular}{|c|c|c|c|c|c|c|c|c|c|}
\hline \multirow{3}{*}{$\begin{array}{l}\text { S. } \\
\text { n }\end{array}$} & \multirow{3}{*}{ Antibiotic } & \multicolumn{4}{|c|}{ S. Paratyphi A } & \multicolumn{4}{|c|}{ S. Typhi } \\
\hline & & \multicolumn{2}{|c|}{ resistant } & \multicolumn{2}{|c|}{ sensitive } & \multicolumn{2}{|c|}{ resistant } & \multicolumn{2}{|c|}{ sensitive } \\
\hline & & No. & $\%$ & No. & $\%$ & No. & $\%$ & No. & $\%$ \\
\hline 1 & $\begin{array}{l}\text { Nalidixic } \\
\text { acid (NA) }\end{array}$ & 17 & 89.42 & 2 & 10.53 & 30 & 96.77 & 1 & 3.35 \\
\hline 2 & $\begin{array}{l}\text { Cotrimoxa- } \\
\text { zole (COT) }\end{array}$ & 4 & 21.05 & 15 & 78.89 & 4 & 12.9 & 27 & 87.09 \\
\hline 3 & $\begin{array}{l}\text { Ciproflo- } \\
\text { xacin (CIP) }\end{array}$ & - & - & 19 & 100 & 3 & 9.67 & 28 & 90.32 \\
\hline 4 & $\begin{array}{l}\text { Chloramp- } \\
\text { henicol (C) }\end{array}$ & - & - & 19 & 100 & - & - & 31 & 100 \\
\hline 5 & $\begin{array}{l}\text { Ceftriaxone } \\
\text { (CTR) }\end{array}$ & - & - & 19 & 100 & - & - & 31 & 100 \\
\hline 6 & $\begin{array}{l}\text { Amoxicillin } \\
\text { (AMO) }\end{array}$ & 2 & 10.53 & 17 & 89.47 & 3 & 9.67 & 28 & 90.32 \\
\hline 7 & $\begin{array}{l}\text { Levoflo- } \\
\text { xacin (LE) }\end{array}$ & - & - & 19 & 100 & 1 & 3.2 & 30 & 96.71 \\
\hline
\end{tabular}

\section{Discussion:}

All the isolates in our study were susceptible to ceftriaxone and chloramphenicol similar to the previous reports from Nepal. ${ }^{4}$ This suggest the possible use of chloramphenicol and third generation cephalosporins in the treatment of enteric fever but the misuse, overuse and self prescription should be discouraged in order to limit the emergence of drug resistance.

In a present study, Nalidixic acid resistance (NAR) was high in both S. Typhi (96.7\%) and S. Paratyphi A (89.2\%) in comparison to the study from Nepal in 2005 which shows $73.3 \%$ and $94.9 \%$ NAR S. Typhi and S. Paratyphi A respectively. ${ }^{5}$ This indicates the increasing trend of reduced susceptibility to fluoroquinolone antibiotics similar to the 
reports from different parts of the world with alarming evidence.

In present study, fluoroquinolone resistant S. Paratyphi A was not observed whereas $3(8 \%)$ isolates of $S$. Typhi were resistant to ciprofloxacin and $1(3 \%)$ was resistant to levofloxacin. Previous study shows 2 ( 5\%) isolates of $S$. Typhi and 2 ( 9\% ) isolates of S. Paratyphi A were resistant to ciprofloxacin. ${ }^{6}$ Comparatively higher drug resistance in S. Typhi than S. Paratyphi A in our study was dissimilar to the previous reports which may be due to lower sample number.

Resistant Salmonella and failure of ciprofloxacin therapy have also been reported from studies conducted in central Nepal. ${ }^{7}$ This may be due to the recommendation of fluoroquinolones as first line therapy for enteric fever, particularly in children, irrespective of sensitivity patterns and without a thorough analysis and assessment of quality of evidence ${ }^{8}$

The decreasing trend of MDR was observed in our study as in other studies from different parts of the world including Nepal. In the present study, ten (20\%) isolates were MDR which is lower in comparison to the report ( $26 \%$ ) from Eastern Nepal in 2004 and MDR S. Typhi (60\%) was lower than reported (92\%) in 2008 from Nepal. ${ }^{9,10}$

Only 1 MDR S. Typhi was observed resistant to levofloxacin by disc diffusion method. Though it shows the significance of the levofloxacin in the treatment of the enteric fever, the NAR strains need higher concentration of fluoroquinolone for the treatment.

\section{Conclusion:}

High level of nalidixic acid resistance and even some fluroquinolone resistance shows the treatment of the enteric fever can not be relied on the fluoroquinolones. It has been an important to perform minimum inhibitory concentration test for the complete evaluation of the fluoroquinolones sensitivity to the nalidixic acid resistant isolates.

\section{Acknowledgements:}

We gratefully acknowledge the support provided by the Bir hospital Hospital, Bhotahity, Kathmandu, Nepal.

\section{Conflict of interest: None}

Funding: None

\section{References:}

1. Tenoner FC. Development and spread of bacterial resistance to antimicrobial agents. Clin Infect Dis 2001;15:108-115.

http://dx.doi.org/10.1086/321834

2. World Health Organization, Department of Vaccines and Biologicals. Treatment of typhoid fever. Background document: the diagnosis, treatment and prevention of typhoid fever. 2003;19-23.

3. Croom KF, Goa KL. Levofloxacin: a review of its use in the treatment of bacterial infections in the United States. Drugs 2003; 64: 2769-802.

http://dx.doi.org/10.2165/00003495-200363240-00008

4. Joshi BG, Keyal K, Pandey R,et al. Clincial profile and sensitivity pattern of Salmonella serotypes in children: A hospital based study. J Nep Paedtr Soc 2011;31:180-3.

5. Shurajawa T, Acharya B, Kinoshita S, et al. Decreased susceptibility to fluoroquinolines and gyr $A$ gene mutation in the Salmonella enterica serovar Typhi and Paratyphi A isolated in Kathmandu, Nepal. Diagnostic Microbilogy and Infectious disease 2006;54:299-303. http://dx.doi.org/10.1016/j.diagmicrobio.2005.10.016

6. Adhikari D, Acharya D, Shrestha P, et al. Ciprofloxacin susceptibility of Salmonella enterica serovar Typhi and Paratyphi A from blood samples of suspected enteric fever patients. Int J Intfect Microbial 2012;1;9-13.

7. Malla S, Kansakar P, Serichantalergs O, et al. Epidemiology of typhoid and paratyphoid fever in Kathmandu: two years study and trends of antimicrobial resistance. J Nep Med Assoc 2005;44:18-22.

8. Thaver D., Zaidi AKM, Critchley J, et al. A comparison of fluoroquinolones versus other antibiotics for treating enteric fever: meta-analysis. BMJ 2009;338.

9. Khanal B, Sharma SK, Bhattacharya SK, et al. Antimicrobial Susceptibility Patterns of Salmonella enteric serotype Typhi in Eastern Nepal. J Health Popul Nutr 2007;25:82-7.

10. Malla S, Dumre SP. Changing trend of antimicrobial resistance toward Salmonella isolates of Nepal; findings of antimicrobial resistance surveillance program, Nepal. ICID, Malaysia 2008;19-22. 